\title{
Implementação da educação escolar indígena Guarani/Kaiowá no território etnoeducacional Cone Sul
}

\author{
Implementation of Guarani/Kaiowá indigenous school education in the \\ ethnoeducational territory Cone Sul
}

\author{
Implementación de la educación escolar indígena Guarani/Kaiowá en el \\ territorio etnoeducacional Cone Sur
}

\author{
Noêmia dos Santos Pereira Moura ${ }^{2}$ \\ Andréia Nunes Militão ${ }^{3}$
}

\begin{abstract}
Resumo: Está em processo a implementação da educação escolar indígena (EEI) no Território Etnoeducacional Cone Sul (TEE), no Mato Grosso do Sul, criado pelo Decreto n. 6861/2009 e desdobrado no Programa Nacional de Territórios Etnoeducacionais (2013). Objetivamos evidenciar tal processo por meio de pesquisa qualitativa, de abordagem do tipo etnográfico, que se ancora no trabalho de campo e na pesquisa documental. A perspectiva analítica é decolonial e realça o processo de resistência e afirmação identitária dos povos Guarani/Kaiowá, historicamente subalternizados em um campo cujos produtores interagem e agem em favor de sua concepção de mundo. Os resultados apontam os Guarani/Kaiowá e suas organizações indígenas como protagonistas na construção das escolas indígenas e evidenciam os movimentos de seus interlocutores.
\end{abstract}

Palavras-chave: Políticas educacionais. Educação escolar indígena. Territórios etnoeducacionais.

\begin{abstract}
The implementation of indigenous school education (IEE) in the Southern Cone Ethno-Educational Territory (TEE) in Mato Grosso do Sul, created by Decree No. 6861/2009 and deployed in the National Program of Ethno-Educational Territories (2013) is in process. We aim to evidence this process through a qualitative research, with an ethnographic approach, which is anchored in field work and in documentary research. The analytical perspective is decolonial and highlights the process of resistance and identity affirmation of the Guarani/Kaiowá peoples, historically subalternized in a field whose producers interact and act in favor of their conception of the world. The results point out the Guarani/Kaiowa and their indigenous organizations as protagonists in the construction of the indigenous schools and show the movements of their interlocutors.
\end{abstract}

Keywords: Educational policies. Indigenous school education. Ethnoeducational territories.

Resumen: Está en proceso la implementación de la educación escolar indígena (EEI) en el Territorio Etnoeducacional Cono Sur (TEE), en Mato Grosso do Sul, creado por el Decreto n. 6861/2009 y desdoblado en el Programa Nacional de Territorios Etnoeducacionales (2013). Objetivamos evidenciar tal proceso por medio de investigación cualitativa, de abordaje del tipo etnográfico, que se ancla en el trabajo de campo y en la investigación documental. La perspectiva analítica es decolonial y subraya el proceso de resistencia y afirmación identitaria de los pueblos guaraní/Kaiowá, históricamente subalternizados en un campo cuyos productores interactúan y actúan en favor de su concepción del mundo. Los resultados apuntan a los Guaraní/Kaiowá y sus organizaciones indígenas como protagonistas en la construcción de las escuelas indígenas y evidencian los movimientos de sus interlocutores.

Palabras clave: Políticas educativas. Educación escolar indígena. Territorios etnoeducativos.

\footnotetext{
${ }^{1}$ Submetido em: 27 mar. 2019 - Aceito em: 01 maio 2019 - Publicado em: 12 nov. 2019.

${ }^{2}$ Universidade Federal da Grande Dourados (UFGD) - E-mail: noemiamoura@ufgd.edu.br

${ }^{3}$ Universidade Estadual de Mato Grosso do Sul (UEMS) - E-mail: andreianunesmilitao@ gmail.com
} 


\title{
Introdução
}

No Brasil, até a década de 1980, a política educacional para os povos indígenas era marcada pelo paradigma civilizatório da política indigenista (NASCIMENTO; VIEIRA, 2011). O artigo apresenta o processo de implementação de um novo projeto de educação escolar indígena (EEI) para esses povos no Brasil e no Território Etnoeducacional Cone Sul (TEE Cone Sul). A intenção é evidenciar a configuração desse novo campo educacional, resultado de interações estabelecidas entre os diversos sujeitos educacionais, desde a década de 1980, cujos princípios norteadores são os seguintes: respeito às territorialidades dos povos indígenas; participação efetiva dos povos indígenas; valorização das identidades de cada povo; diálogo e articulação entre as instituições; e coordenação das políticas de educação escolar indígena.

Trazemos aqui elementos da dimensão sociopolítica, que, segundo Marli André (2009, p. 44), “[...] inclui uma reflexão sobre o momento histórico, sobre as forças políticas e sociais e sobre as concepções e valores presentes na sociedade". Nesse sentido, a contradição é pauta contínua nas políticas públicas educacionais resultantes do novo normativo. Por isso, para implementar as conquistas legais, os movimentos indígenas têm de estar posicionados; pressionando em fóruns, seminários e atuando em comissões, conselhos, entre outras organizações que tratam da temática da EEI. Nesse processo, empoderam-se continuamente.

A perspectiva analítica por nós assumida, portanto, é de cunho decolonial e está ancorada nos recentes debates empreendidos pelo coletivo de pesquisadores da Modernidade-Colonialidade-Decolonialidade (M/C/D), que se posicionam criticamente a partir de categorias como colonialidade do poder, do ser e do saber e interculturalidade crítica. O conceito de colonialidade do saber significa todo o processo de submissão e assujeitamento do "Outro" (alter) com base em relações de poder e dominação à força, bem como atitudes de cooptação e conquista. Para o pesquisador Elias Nazareno (2017), o caminho alternativo à colonialidade do poder é a decolonialidade.

\begin{abstract}
A interculturalidade crítica, entendida como processo social, político e epistêmico, pode ser considerada, portanto, como sinônimo da decolonialidade, pois, mesmo tendo em conta as relações assimétricas estabelecidas pelo colonizador em termos políticos, sociais e epistêmicos, não há como negar a influência recíproca exercida por parte daqueles que foram historicamente subalternizados. $[\ldots]$ Os povos indígenas que permanecem vivos, com seus conhecimentos e suas línguas, são uma prova viva da decolonialidade como processo de resistência e afirmação identitária (NAZARENO, 2017, p. 46, grifo nosso).
\end{abstract}

Acrescentamos que, no conjunto das práticas decoloniais dos povos indígenas, destaca-se a ressignificação das escolas para índios em escolas indígenas, as quais estão passando por processo de reconhecimento de sua natureza indígena - elaboração de projetos políticos pedagógicos, regimentos, calendários, currículos específicos e produção de materiais didáticos bilíngues no campo da EEI.

Ressaltamos, também, o conceito de campo de Bourdieu (2003), o qual nos auxilia a compreender ações e movimentos dos sujeitos educacionais produtores dessas políticas 
educacionais específicas para os povos indígenas no país. O campo é um espaço social de relações e interações objetivas e subjetivas, no qual cada sujeito educacional tem sua posição demarcada e, por isso, a cada estratégia de operação interage diretamente com outros agentes, produzindo uma nova reconfiguração posicional e, consequentemente, sua recomposição. Segundo o autor, é fundamental "Compreender a gênese social de um campo, e apreender aquilo que faz a necessidade específica da crença que o sustenta, do jogo da linguagem que nele se joga, das coisas materiais e simbólicas em jogo que nele se geram [...]" (BOURDIEU, 2003, p. 69).

Consideramos produtores do campo da EEI as instituições envolvidas no Ministério da Educação (MEC), nas Secretarias de Educação (do estado e dos municípios), a Fundação Nacional do Índio (FUNAI), as universidades que oferecem formação para profissionais indígenas, as organizações não governamentais - no caso de Mato Grosso do Sul (MS), o Conselho Indigenista Missionário (CIMI) e a Missão Caiuá -, as organizações indígenas, assim como as pessoas indígenas e as não indígenas. Dentre os agentes destacamos as lideranças Guarani/Kaiowá que consideramos protagonistas centrais no campo em construção. Ao invés de serem cooptados e acomodados no âmbito das escolas, vêm paulatinamente moldando-as e adaptando-as às necessidades de sua comunidade. Segundo Nascimento (2013), os povos indígenas vêm se movimentando no sentido de ressignificar a escola dos brancos em Escolas Indígenas, apropriando-se de sua estrutura políticopedagógica e administrativa.

Com base em abordagem qualitativa, na pesquisa do tipo etnográfica, empírica e documental (ANDRÉ, 2009; LÜDKE; ANDRÉ, 2013), analisamos a documentação que normatiza a educação escolar indígena, organizada por territórios etnoeducacionais (2009), o Programa Nacional de territórios etnoeducacionais (BRASIL, 2013) e o TEE Cone Sul, no estado de MS e fizemos trabalho de campo. Dialogamos com vários sujeitos educacionais: secretários municipais de educação, técnicos, coordenadores responsáveis pela educação escolar indígena, diretores, coordenadores, secretários, professores e outros servidores das escolas indígenas, cuja maioria é Guarani/Kaiowá e recolhemos dados sobre ações dos municípios e do estado em parceria com o MEC. Essa vivência pôs em relevo o processo de constituição da política educacional.

A imersão em campo considerou o lugar de atuação docente dos egressos da Licenciatura Intercultural Indígena Teko Arandu. A inserção dos egressos nas áreas e níveis de formação específica é tema da pesquisa e supervisão de pós-doutorado desenvolvidas na Universidade Estadual de Mato Grosso do Sul (UEMS) pelas autoras deste artigo.

As seguintes questões nortearam a análise documental e os dados de campo: Como está sendo implementada a EEI no Território Etnoeducacional Cone Sul? Como está se dando o PNTEE no etnoterritório? Como está sendo desenvolvido o Plano de Ação, como têm sido seu acompanhamento e avaliação? Qual o papel dos movimentos sociais indígenas nesse processo? Para respondê-las, dividimos o texto em seções a fim de evidenciar os seguintes aspectos: a) a educação escolar indígena no Programa Nacional de Territórios Etnoeducacionais; b) o movimento do TEE Cone Sul; c) os avanços e os desafios na perspectiva de professores e pesquisadores Guarani/Kaiowá e na de não indígenas. 


\section{A EEI no programa nacional de territórios etnoeducacionais (PNTEE)}

A educação escolar indígena nasce das demandas apresentadas pelos povos indígenas ao Estado brasileiro, no momento do processo de elaboração da Constituição Federal, e ganha status de política educacional com a Lei de Diretrizes e Bases da Educação, em 1996 (BRASIL, 1996). A seguir, evidenciamos os dispositivos que tratam dos territórios etnoeducacionais para nos determos na análise do Decreto n. 6861/2009, que dispõe sobre a educação escolar indígena e define sua organização em territórios etnoeducacionais; na análise da Resolução CEB/CNE n. 05/2012, atinente às Diretrizes Curriculares Nacionais para a educação Escolar Indígena na Educação Básica e na Portaria n. 1.062/2013, que institui o Programa Nacional dos Territórios Etnoeducacionais (PNTEE).

Os territórios etnoeducacionais - como um novo arranjo da política da educação escolar indígena - instituem " [...] uma nova base política e administrativa de planejamento e gestão das políticas e ações da educação escolar indígena no Brasil” (LUCIANO, 2010, p. 1). Para Nascimento (2013, p. 339), tratam-se de "resposta do Estado aos dilemas da gestão das políticas de EEI, sobretudo no tocante à participação e protagonismo dos indígenas na formulação e no acompanhamento das ações afetas a essa área”.

A redefinição das esferas de responsabilidade situa-se no início da década de 1990, quando

[...] se transfere da Funai para o MEC a responsabilidade pela coordenação e promoção das políticas de educação escolar indígena, é definido o regime de colaboração como forma de planejamento e execução, atribuindo-se à União o papel de legislar e coordenar as políticas e, aos estados, de ofertar e executar essa modalidade de educação (NASCIMENTO, 2013, p. 341).

Observemos o protagonismo dos povos indígenas na definição relativa aos territórios etnoeducacionais. Segundo Nascimento (2013, p. 339-340), esse processo, conduzido pelo MEC, se dá,

[...] por meio de consulta aos povos indígenas interessados e da articulação política que o Ministério faz junto às instituições envolvidas e responsáveis pela educação escolar indígena, tais como as secretarias de educação, as instituições federais de educação profissional e tecnológica, as universidades, a própria Funai e organizações da sociedade civil.

A proposta dos TEE é "superar os entraves no âmbito do Regime de Colaboração e da organização dos Sistemas de Ensino no Brasil” (BRASIL, 2009a, p. 2). A nova organização constitui avanço no cenário educacional, pois adota como parâmetro a territorialidade das etnias, o que exige ampla participação da população indígena na definição das políticas educacionais específicas. Além disso, resguarda exclusividade de lotação ao professor indígena pertencente à comunidade:

I - a centralidade do território para o bem viver dos povos indígenas e para seus processos formativos e, portanto, a localização das escolas em terras habitadas por comunidades indígenas, ainda que se estendam por territórios de diversos Estados ou Municípios contíguos; [...] 
IV - a exclusividade do atendimento a comunidades indígenas por parte de professores indígenas oriundos da respectiva comunidade (BRASIL, 2009b, p. 2).

Sousa (2017, p. 59) observa que o desenho oportuniza a participação ativa dos indígenas, posto que "[...] a construção de territórios etnoeducacionais reestabelece grande parte do significado e da força do território como espaço vital da existência indígena".

Sobre a organização, a estrutura e o funcionamento da escola indígena, o Decreto $\mathrm{n}$. 6861/2009 indica como elementos básicos: "I- sua localização em terras habitadas por comunidades indígenas; II- exclusividade de atendimento a comunidades indígenas; IIIensino ministrado nas línguas maternas das comunidades atendidas; e IV- organização escolar própria" (BRASIL, 2009). Essa organização, que envolve também o apoio técnico e financeiro da União, demanda a escuta dos múltiplos agentes que compõem o território, incluindo as comunidades indígenas, os agentes estatais locais e nacionais, conforme indica o referido decreto.

O normativo prevê para cada território etnoeducacional a elaboração de um plano de ação que deve contemplar o seguinte:

I- diagnóstico do território etnoeducacional com descrição sobre os povos, população, abrangência territorial, aspectos culturais e linguísticos e demais informações de caráter relevante;

II- diagnóstico das demandas educacionais dos povos indígenas;

III- planejamento de ações para o atendimento das demandas educacionais;

IV- descrição das atribuições e responsabilidades de cada partícipe no que diz respeito à educação escolar indígena, especialmente quanto à construção de escolas indígenas, à formação e contratação de professores indígenas e de outros profissionais da educação, à produção de material didático, ao ensino médio integrado à educação profissional e à alimentação escolar indígena (BRASIL, 2009).

Tais ações foram replicadas no Programa Nacional dos Territórios Etnoeducacionais, designado por meio da Portaria n. 1.062, de 30 de outubro de 2013, que estabeleceu "um conjunto articulado de ações de apoios técnico e financeiro do Ministério da Educação - MEC aos sistemas de ensino, para a organização e o fortalecimento da educação escolar indígena". Segundo o Programa, os territórios etnoeducacionais são "[...] espaços institucionais em que os entes federados, as comunidades indígenas, as organizações indígenas e indigenistas e as instituições de ensino superior pactuam as ações de promoção da educação escolar indígena [...]" (BRASIL, 2013a).

O PNTEE engloba diversas ações para atender às necessidades do TEE, tais como as de gestão educacional e participação social com formação para equipes gestoras dos sistemas de ensino sobre o etnoterritório e suas especificidades, incluindo desenvolvimento de metodologias próprias para o ensino nas escolas indígenas. Igualmente prevê o desenvolvimento de pesquisas para a publicação de materiais didáticos e paradidáticos bilíngues ou monolíngues em língua materna. Inclui, ainda, preocupação com o atendimento às necessidades de transporte e alimentação escolar para as escolas indígenas; com o incentivo à Educação de Jovens e Adultos (EJA), articulada à formação profissional; com o prosseguimento dos estudos em nível de graduação e pós-graduação para os estudantes 
indígenas e com o incentivo ao desenvolvimento de pesquisa com temáticas ligadas à educação escolar indígena.

Até 2018, foram pactuados 25 TEE, que atualmente estão inseridos no PNTEE. Sousa (2016) constata que há desconhecimento, por parte dos sistemas de ensino e das organizações indígenas, da política educacional etnoterritorializada, o que gera dúvidas quanto à possibilidade real de melhorias na educação escolar indígena.

O PNTEE apresentava-se na forma de ações descentralizadas e induzidas pela Secretaria de Educação Continuada, Alfabetização, Diversidade e Inclusão (SECADI/MEC), envolvendo várias pessoas e instituições, por exemplo, as universidades, a secretaria estadual e as secretarias municipais de educação, sempre acompanhadas e avaliadas pelas lideranças indígenas em suas organizações. Entretanto, a SECADI foi dissolvida em 2019 e ainda não temos informações suficientes para avaliar o resultado de seu desmonte.

\section{O TEE Cone Sul no estado de Mato Grosso do Sul}

Contextualizamos o estado de Mato Grosso do Sul e os povos Guarani/Kaiowá, que vivem a implementação da educação escolar indígena no Território Etnoeducacional Cone Sul, para termos a dimensão das dificuldades dos entes federados no sentido de dialogar e desenvolver ações em regime colaborativo.

Mato Grosso do Sul divide-se em 79 municípios e cada um tem autonomia para aceitar ou não a parceria com a Secretaria Estadual de Educação no que se refere ao atendimento às comunidades indígenas. No estado há dois territórios etnoeducacionais. $\mathrm{O}$ TEE Cone Sul, dos Guarani/Kaiowá, e o Povos do Pantanal, dos Terena, Guató, Kinikinao, Kadiwéu, Ofaié e Atikum. Juntos, os etnoterritórios somam 83.434 pessoas indígenas (BRASIL, 2019).

Marcado por intensos conflitos fundiários, notadamente ampliados a partir da década de 1970, com o surgimento de sucessivos movimentos de retomada dos territórios tradicionalmente ocupados pelos povos indígenas na região, o estado é considerado um dos mais violentos no tocante à luta fundiária. Apesar disso, fortalecidos pelos movimentos políticos em nível nacional, "[...] os índios começam a emergir de um processo de resistência já existente, mas, ainda assim, subjugados pela política de Estado que descaracterizava o quadro de diversidade e desestruturava, no interior das comunidades, o conceito e o desejo de alteridade" (NASCIMENTO; VIEIRA, 2011, p. 4-5, grifo do original). Criam o Movimento de Professores Guarani/Kaiowá (MPGK), por meio do qual reivindicam formação específica para os professores Guarani/Kaiowá e escolas que atendam às demandas de suas comunidades.

Atualmente, há 44 Terras Indígenas de povoamento tradicional, de acordo com dados do site da FUNAI. Crespe (2015, p. 133) destaca que, "[...] além da violência física, os Guarani/Kaiowá são vítimas dos estereótipos construídos a partir de adjetivos negativos, como preguiçosos e bêbados, muitas vezes veiculados pela imprensa regional”. Assim, a carga de preconceito e discriminação acompanha a história dessas populações. Por isso, a 
preocupação das lideranças indígenas em matricular seus filhos nas cidades ou fora de suas comunidades.

Das 44 áreas indígenas, somente 31 possuem escolas que são ou estão em processo de reconhecimento como Escolas Indígenas. As demais ainda estão desatendidas pelo poder público e demandam constantemente o Estado brasileiro. Nesse sentido, a possibilidade de se constituir um novo arranjo territorial que transponha a atual divisão político-administrativa do território nacional é um avanço do MEC, na perspectiva dos povos indígenas (LUCIANO, 2010). Essa visão do território como ponto de partida para as demais iniciativas soa bem para os Guarani/Kaiowá.

[...] apresento o significado de tekoha, a partir da etimologia da palavra. Teko significa modo de ser e ha é um indicativo de lugar. Assim, o uso mais comum do termo é para se referir a um lugar onde se viveu, se vive ou se pode viver o teko, o modo de ser kaiowá. Este modo de ser não pode ser de qualquer jeito; muito pelo contrário, o modo de ser que os Kaiowá e os Guarani se referem é o bom modo de ser (modo reto, certo), chamado de teko porã (CRESPE, 2015, p. 25).

Notamos que o princípio da vida Guarani/Kaiowá é o tekoha. Isso implica que a luta pela educação etnoterritorializada está conectada à territorialidade dos Guarani/Kaiowá que seguem afirmando: "Sem Tekoha não há Teko. Sem Tekoha não há escola indígena" (BRASIL, 2013b).

Para melhor compreendermos o TEE Cone Sul, organizamos um quadro no qual indicamos as escolas indígenas por município e as terras indígenas, destacando a situação da escola (o número, o nome e o nível de escolaridade oferecido) e da terra indígena, a partir de dados documentais oriundos das secretarias municipais e das escolas indígenas.

Quadro 1. Escolas Indígenas Guarani/Kaiowá no Território Etnoeducacional Cone Sul em 2018

\begin{tabular}{|c|c|}
\hline Município & Número/ Nome/ Nível/ Situação da Terra Indígena \\
\hline 1) Juti & $\begin{array}{l}\text { 50029959/EM Indígena Mbo-Ero Arandui (Educação Infantil/EI ao } 5^{\circ} \text { ano/multisseriado - } \\
\text { TI Jarará - Aldeia Jarará -homologada) } \\
\text { 50079808/ EM Indígena Mbo Eroga Taperandi Taquara (EI ao } 5^{\circ} \text { ano/multisseriado - TI } \\
\text { Aldeia Taquara - declarada) }\end{array}$ \\
\hline 2) Maracaju & $\begin{array}{l}\mathbf{5 0 0 4 9 8 0 1 / E M ~ I n d i ́ g e n a ~ V e l a ́ r i o ~ S u c u r i y ~ ( E I ~ a o ~} 5^{\circ} \text { ano/multisseriado - TI Sucuri'y - } \\
\text { registrada) }\end{array}$ \\
\hline $\begin{array}{l}\text { 3) Coronel } \\
\text { Sapucaia }\end{array}$ & $\begin{array}{l}\text { 50019597/EM Nande Reko Arandu (EI ao } 9^{\circ} \text { ano - TI/Reserva Taquaperi - registrada) } \\
\text { 50032992/ Mbo Eroy Arandu (EI ao } 9^{\circ} \text { ano - TI/Reserva Taquaperi - registrada) } \\
\text { Extensão: } \\
\text { 50019554 Escola Estadual Coronel Sapucaia (Ensino Médio /EM - TI Taquaperi/Reserva - } \\
\text { registrada) }\end{array}$ \\
\hline 4) Dourados & $\begin{array}{l}\mathbf{5 0 0 1 6 2 4 5 / E M ~ I n d i ́ g e n a ~ T e n g a t u i ~ M a r a n g a t u ~ - ~ P o l o ~ ( E I ~ a o ~} 9^{\circ} \text { ano - TI/Reserva Dourados, } \\
\text { Aldeia Jaguapiru - regularizada) } \\
\mathbf{5 0 0 3 0 0 4 3 / E M ~ I n d i ́ g e n a ~ A g u s t i n h o ~ ( E I ~ a o ~} 9^{\circ} \text { ano - TI/Reserva Dourados, Aldeia Bororo - } \\
\text { regularizada) } \\
\mathbf{5 0 0 3 0 4 2 6 / E M ~ I n d i ́ g e n a ~ A r a p o r a ̃ ~ ( E I ~ a o ~} 9^{\circ} \text { ano - TI/Reserva Dourados, Aldeia Bororo - } \\
\text { regularizada) } \\
\text { 50060007/EM Indígena Ramão Martins (EI ao } 9^{\circ} \text { ano }-\mathrm{TI} / \text { Reserva Dourados, Aldeia } \\
\text { Jaguapiru - regularizada) } \\
\mathbf{5 0 0 4 0 6 0 0 / E M ~ I n d i ́ g e n a ~ L a c u ~ I ~ R o q u e ~ I s n a r d ~ ( E I ~ a o ~} 5^{\circ} \text { ano - TI/Reserva Dourados, Aldeia } \\
\text { Bororo - regularizada) } \\
\mathbf{5 0 0 3 0 3 8 8 / E E I ~ d e ~ E M ~ I n t e r c u l t u r a l ~ G u a t e k a ~ M a r c ̧ a l ~ D e ~ S o u z a ~}\left(\mathrm{EM} \mathrm{e} 6^{\circ} \text { ao } 9^{\circ}-\mathrm{TI} / \text { Reserva }\right.\end{array}$ \\
\hline
\end{tabular}


5) Eldorado

6) Laguna Carapã

7) Antônio João

8) Caarapó

9) Tacuru

10) Paranhos

11) Amambai

12) Douradina

13) Japorã

\begin{tabular}{|l|} 
\\
\hline 14) Bela Vista \\
15) Aral Moreira \\
\hline
\end{tabular}

Dourados, Aldeia Jaguapiru - regularizada)

50016130/EM Francisco Meireles Missão Evangélica Caiua ( EI ao $9^{\circ}$ ano - não indígena) 50029495/EM Indígena Pa I Chiquito- Chiquito Pedro (EI ao $9^{\circ}$ ano - TI Panambizinho regularizada)

Extensão:

50017373/EE Presidente Getúlio Vargas (EM - Vila Vargas/Dourados - funciona no prédio da EM Chiquito Pedro)

50029886/EM Indígena Mbo Eroy Rendy - Polo (EI ao $9^{\circ}$ ano - TI Cerrito - regularizada)

50029908/Mbo Eroy Jeguaka Poty Escola Cocar De Flores (EI ao $9^{\circ}$ ano - TI Guaimbé regularizada)

50029916/Mbo Eroga Okara Poty Escola Terreiro De Flores (EI ao $9^{\mathbf{0}}$ ano - TI Rancho Jacaré - regularizada)

50024655/EM Mbo Eroy Tupa I Arandu Renoi (EI ao $9^{\circ}$ ano - TI Nande Ru Marangatu homologada)

$\mathbf{5 0 0 3 0 8 8 4}$ /EE Indígena de EM Yvy Poty (EM - TI Caarapó/Reserva - regularizada)

50028375/EM Indígena Nandejara-Polo (EI ao $9^{\circ}$ ano - TI/Reserva Caarapó/Aldeia

Te'Ykuê - regularizada)

Extensão:

Sala M’Bocajá (EI ao $5^{\circ}$ ano)

Sala Saverá (EI ao $5^{\circ}$ ano)

Sala Loide Bonfim (EI ao $5^{\circ}$ ano)

50029894/EMI Ubaldo Arandu Kwe-Mi - Polo (EI ao $9^{\circ}$ ano - TI/Reserva Sassoró regularizada)

50034090/EEI Jasy Rendy Aldeia Sassoró (EM - TI Sassoró/Reserva - regularizada)

50033050/EM Tomázia Vargas (EI ao $9^{\circ}$ ano - TI Jaguapiré - regularizada)

50021591/EM Prof. Adriano Pires (EI ao $9^{\circ}$ ano - TI Reserva Pirajuí - regularizada)

Extensão:

Sala Potrero Guaçu (EI ao $6^{\circ}$ ano + EJA - TI Potrero Guaçu - declarada)

Sala Missão Caiuá ( EI ao $7^{\circ}$ ano, sendo o $6^{\circ} / 7^{\circ}$ EJA $3^{\text {a }}$ fase + EJA - não indígena)

50022636/EM Pancho Romero ( EI ao $6^{\circ}$ ano + EJA - Terra Indígena

Takuaraty/Yvykuarusu Aldeia Paraguassu - homologada)

Extensão:

Sala Arroio Corá ( EI ao $5^{\circ}$ ano e $6^{\circ} / 7^{\circ}$ EJA $3^{\text {a }}$ fase - TI Arroio-Korá - homologada)

Sala Arandupoty (EI ao $5^{\circ}$ ano - TI YPoi - delimitada)

Sala Princesa Isabel (EI ao $5^{\circ}$ ano e $6^{\circ} / 7^{\circ}$ EJA $3^{a}$ fase - Terra Indígena Sete Cerro homologada)

50015141/EMP Indígena Mbo Eroy Guarani Kaiowá (EI ao $9^{\circ}$ ano - TI/Reserva Amambai - regularizada)

Extensão:

Sala Pandui (EI ao $5^{\circ}$ ano/multisseriada - TI Amambai/Reserva - regularizada)

50029010/EM Polo Indígena Mbo Erenda Tupa I Nandeva (EI ao $9^{\circ}$ ano - TI Limão

Verde/Reserva - regularizada)

Extensão:

Sala/Jaguari (EI ao $5^{\circ}$ ano/ multisseriada - TI Jaguari - regularizada)

50030370 EE Indígena Mbo'eroy Guarani Kaiowá (EM - TI/Reserva Amambai regularizada)

50029037/EM Mita Rory (EI ao $5^{\circ}$ ano - Escola da Missão Caiuá - não indígena)

50029754/EMI Joaozinho Carape Fernando (EI ao $9^{\circ}$ ano - TI Panambi- Lagoa Rica delimitada)

50029460/EM De Eief Mbo Ehao Tekoha Guarani Polo (EI ao $9^{\circ}$ ano - TI/Reserva Porto

Lindo - regularizada)

Extensões:

Escola da Missão Caiuá (EI)

Sabedoria Tradicional $\left(1^{\circ}\right.$ ao $\left.5^{\circ}\right)$

Escolinha de Vidro $\left(1^{\circ}\right.$ ao $\left.5^{\circ}\right)$

Fonte: Elaborado pelas autoras a partir da pesquisa de campo. 50024213/EM Indígena Piracua (EI ao $9^{\circ}$ ano, sendo $5^{\circ}, 6^{\circ} / 7^{\circ}, 8^{\circ} / 9^{\circ}-$ TI Pirakua regularizada)

50029789/EPMI Arandu Renda Guarani Kaiowá (EI ao $9^{\circ}$ ano - TI Aldeia Guasuty) 
Identificamos 32 Escolas Indígenas, 15 salas de aula extensão das escolas polo indígenas e duas extensões do ensino médio na TI Jaguapiré e na TI Panambizinho. Essas escolas situam-se em 15 municípios e em 26 Terras Indígenas. Constatamos que das 8 TI/Reservas, delimitadas entre 1918-1928, 7 oferecem educação básica completa. A TI/Reserva Pirajuí é a única que não oferece o ensino médio. Das outras 18 Terras Indígenas, reconhecidas de 1980 para cá, 14 oferecem educação infantil e ensino fundamental completo e 4 oferecem educação infantil e ensino fundamental incompleto (até o $6^{\circ}$ ano). Para pleitear a implantação de novos níveis, segundo avaliação das lideranças indígenas, é necessário ter professores Guarani/Kaiowá habilitados em todos os níveis e em todas as áreas/disciplinas. Essas e outras demandas constituíram o Plano de Ação do TEE Cone Sul.

O Plano de Ação foi elaborado no início do processo de pactuação em 2009. No ano seguinte, contratou-se o consultor Tonico Benites para realizar o diagnóstico do etnoterritório, que foi finalizado e apresentado em 2011. Na ocasião foram escolhidos os membros da Comissão Gestora, que havia sido criada pela Portaria do MEC n. 931/2011 (BRASIL, 2011). À Comissão competia acompanhar, avaliar e revisar o Plano de Ação. No plano, estavam definidas as demandas e as instituições responsáveis por desenvolvê-las. Contudo, algumas questões político-financeiras ficaram pendentes, mesmo após a criação do PNTEE, que previa a descentralização de apoio técnico e financeiro.

De acordo com as lideranças indígenas do Fórum Estadual de Educação Escolar Indígena de Mato Grosso do Sul (FOREEIMS) e do MPGK, a comissão gestora criada e nomeada pela SED/MS, não recebeu suporte técnico e financeiro para desenvolver suas atividades, o que fez com que houvesse uma lacuna na implementação do PNTEE. Destarte, o campo da EEI continuou avançando no MS, devido aos esforços e ao protagonismo das organizações dos professores e das lideranças indígenas de ambos os territórios.

O que realmente está em movimento é a Comissão do Fórum de Educação Escolar Indígena, que agrega os povos representantes dos TEE Cone Sul e os Povos do Pantanal e cumpre o papel de acompanhar, avaliar e demandar o estado de MS e o MEC, por intermédio de seus representantes nos Conselhos de Educação (dos municípios e do estado) e na Comissão Nacional de Educação Escolar Indígena (CNEI). No TEE Cone Sul, além do FOREEIMS, movimentam-se os membros da Aty Guasu e os do Movimento de Professores Guarani/Kaiowá.

Em diálogo com técnicos e secretários do TEE Cone Sul, percebemos que alguns conheciam o decreto, mas desconheciam o período de sua vigência; outros (a maioria) não tinham conhecimento do PNTEE. Questionados sobre quem representava o município na Comissão Gestora do etnoterritório, poucos souberam informar. Afirmaram ter respondido, recentemente, ao Ministério Público sobre os critérios de lotação dos professores indígenas. Daí deduzirmos que a Comissão Gestora não conseguiu envolver as secretarias municipais e as demais instituições e organizações. 


\section{Avanços e desafios}

No ano de 2018, acompanhamos duas reuniões da Comissão do FOREEIMS e o XXIV Encontro de Lideranças e Professores Guarani/Kaiowá, organizado pelo MPGK. Esses eventos são os fóruns nos quais as lideranças das comunidades e das escolas avaliam o desenvolvimento das ações governamentais e produzem documentos por meio dos quais apresentam suas demandas. Essa tática tem sido significativa, posto que dá continuidade às ações de controle social do etnoterritório pelos Guarani/Kaiowá.

Conforme o Artigo 5ª do Decreto n. 6861/2009 (BRASIL, 2009), o MEC prestará apoio técnico e financeiro às ações do Plano de Ação do TEE que forem veiculadas no Plano de Ações Articuladas (PAR) no sentido de viabilizar construção de escolas; formação inicial e continuada de professores indígenas e de outros profissionais da educação; produção de material didático; ensino médio integrado à formação profissional; e alimentação escolar indígena. Tendo em vista tais observações, realçamos a avaliação das organizações indígenas sobre o processo de implementação da EEI no TEE Cone Sul, nas duas reuniões da Comissão do Fórum de Educação Escolar Indígena e no XXIV Encontro de Professores e Lideranças Guarani/Kaiowá, realizado pelo MPGK.

A primeira reunião foi no dia 18 de agosto, na sede do Sindicato dos Bancários, em Dourados; o assunto em pauta foi a elaboração de um documento a ser entregue aos candidatos indígenas e aos não indígenas, parceiros nas causas indígenas. A segunda reunião realizou-se no dia 15 de dezembro, no Anfiteatro Central da UEMS, e teve como pauta: Conjuntura da Política Indigenista e da Educação; avaliação das políticas afirmativas, desafios e estratégias de ação. O Encontro do MPGK aconteceu entre os dias 07 e 10 de novembro de 2018, na Aldeia Cerrito/Eldorado.

Para as lideranças indígenas presentes nesses eventos, alguns avanços podem ser destacados, tais como: 1) atuação da Universidade Federal da Grande Dourados (UFGD) e da Universidade Federal de Mato Grosso do Sul (UFMS) na formação específica de um número representativo de professores nas licenciaturas interculturais (Teko Arandu e Povos do Pantanal); 2) desenvolvimento da formação de professores no curso de magistério intercultural em nível médio (Ára Verá e Povos do Pantanal) pelo Centro Estadual de Formação de Professores Indígenas na Secretaria Estadual de Educação (CEFPI); 3) construção de novos prédios escolares por meio da parceria entre os entes federados (MEC, Secretarias de Educação - municipais e estadual); 4) descentralização de recursos para atender a educação escolar indígena, por meio do Programa de Ação Articulada (PAR/MS) e dos territórios etnoeducacionais Cone Sul e Povos do Pantanal; 5) abertura de espaços de participação e representação indígena nas secretarias de educação, garantidos em leis, desde 1992; 6) criação do Centro de Formação de Professores Indígenas no Estado para o qual foi destinada verba específica; criação de núcleos ou outros espaços de gestão da educação escolar indígena em órgãos municipais e estadual de educação; 7) formação continuada de professores indígenas pelo Programa "Ação saberes Indígenas na Escola"; 8) criação do Programa Bolsa Permanência Indígena para atender os indígenas nas universidades em cursos técnicos e bacharelados; 9) aumento do número de professores indígenas (Mesa de avaliação 
da Comissão FOREEIMS, 18 de agosto de 2018); 10) abertura de escola em 2019, nas TI Guiraroká/Caarapó, TI Pyielito Kuê, Lima Campo/Ponta Porã; 11) assento do FOREEIMS no Conselho Estadual de Educação; 12) aumento de professores indígenas no MS, perfazendo mais ou menos 1.200 ; 13) participação de delegados do MS na Conferência Nacional de Educação (CONAE) 2018; 14) desenvolvimento de materiais didáticos específicos; 15) entrega de propostas da Comissão do FOREEIMS aos candidatos ao Parlamento Federal, em agosto; 16) escolas indígenas com prédios novos e próprios, de formato padrão; 17) coordenações pedagógicas, em sua maioria, composta por professores indígenas; 18) merenda e cardápio específico; 19) transporte escolar; 20) corpo técnico composto por indígenas; 21) Projetos Pedagógicos e Regimentos próprios ou em fase de finalização; 22) seletivo de professores, preferencialmente indígenas e habilitados em nível médio e superior; 23) internet.

Nessa direção ressaltamos os movimentos dos membros responsáveis pelo desenvolvimento do Plano de Ação do TEE Cone Sul. As universidades (UFGD, UEMS e Universidade Católica Dom Bosco (UCDB)) atenderam os acadêmicos indígenas com programas próprios e com financiamento de organizações parceiras. Quatro programas em rede se destacaram: 1) Programa Rede de Saberes, financiado pela Fundação Ford entre 2008 e 2018, por meio do qual se desenvolveram ações de apoio à permanência dos estudantes indígenas nos cursos da UCDB, da UFMS, da UFGD e da UEMS; 2) Programa de Bolsa Permanência Indígena, financiado pelo FNDE. Com a bolsa os alunos custeavam suas despesas com material didático, transporte e moradia; 3) Programa Ação Saberes Indígenas na Escola, em que as atividades de formação foram distribuídas em polos, entre a UCDB, a UFGD, a UEMS e a UFMS. As temáticas centrais foram numeramento e letramento e o objetivo era produzir materiais didáticos para as escolas indígenas; e, 4) Programa Observatório de Educação, financiado pela CAPES. A UCDB ofereceu as primeiras bolsas de pós-graduação em nível de mestrado e doutorado, em parceria com a UFGD, a UEMS e a UFMS, na modalidade projetos interinstitucionais, por meio do Observatório de Educação (OBEDUC), induzido pela CAPES entre 2011-2018. Foram aprovados três projetos OBEDUC - o primeiro foi específico para a educação escolar indígena.

A UFGD investiu na Faculdade Intercultural Indígena (FAIND), que abrigou a Licenciatura Intercultural Indígena Teko Arandu, diplomou 225 professores Guarani/Kaiowá (e mantém outras turmas em formação); ofertou a especialização em educação escolar indígena (2017) e selecionou a primeira turma do Mestrado em Educação e Territorialidade.

A SED/MS, coordenadora das ações dos TEE Cone Sul e Povos do Pantanal, custeou o Centro de Formação de Professores Indígenas (CEFPI/MS), que ofereceu os cursos de Magistério Intercultural em nível Médio nos dois etnoterritórios. Além disso, descentralizou os recursos do PAR para os municípios subsidiarem as escolas indígenas.

Notamos que o campo da educação escolar indígena está em construção e três ações precisam ser acompanhadas: 1) a extinção da SECADI, no âmbito do MEC; 2) a estadualização do $6^{\circ}$ ao $9^{\circ}$ anos; e, 3) a multisseriação.

Desde 2016, após o “golpe jurídico-midiático-parlamentar” (SAVIANI, 2016, p. 390), 
o governo brasileiro vem anunciando a extinção da SECADI. Em relação a essa questão, o documento final do VII Fórum Estadual de Educação Escolar Indígena (VINHA, 2016), assinado por mais de 600 participantes, faz a seguinte avaliação:

\begin{abstract}
Entendemos que a extinção da SECADI, por sua vez, arrancará do âmbito do Ministério de Educação a Secretaria que representa princípios de cidadania, inclusão e combate a todas as formas de intolerância e discriminação, presentes na Constituição da República Federativa do Brasil. A SECADI tem sido um dos poucos espaços de interlocução dos povos indígenas para implementar políticas públicas nas áreas de educação escolar indígena, especialmente a política dos territórios etnoeducacionais, conforme o decreto 6861/2009, que define sua organização em territórios etnoeducacionais (Documento Final, 2016 apud VINHA, 2016, p. 18-19).
\end{abstract}

A confirmação da extinção da SECADI, no início de 2019, sinaliza um cenário de dificuldades para a consolidação da educação escolar indígena. Há preocupação das lideranças com as políticas educacionais em andamento. Como a maioria dos estados e dos municípios acompanham as ações do MEC, pode ser que fique mais difícil conquistar espaços nas secretarias municipais. Além do que, a educação escolar indígena também perde espaço dentro da esfera federal.

Por sua vez, os municípios e o estado de MS fazem parceria e permuta no tocante à oferta do ensino fundamental, que começa a vigorar em 2018. Configura-se, assim, o processo de estadualização do $6^{\circ}$ ao $9^{\circ}$ ano e de municipalização dos anos iniciais do ensino fundamental. A cada ano o estado assume um ano final e repassa um inicial para o município. Algumas questões se colocam: O estado vai manter os alunos na Terra Indígena e vai ampliar a estrutura das escolas estaduais ou vai transportar os estudantes para as cidades? Em levando os estudantes para a cidade, como ficarão os professores indígenas que não tiverem salas constituídas?

Paralelamente, há um movimento de esvaziamento de classes nas escolas indígenas e a ameaça do retorno às turmas multisseriadas. Amplia-se a procura por vagas nas escolas da cidade, desde a educação infantil ao ensino médio. Algumas das alegações dadas pelas famílias e destacadas pelos professores indígenas: "as escolas da cidade oferecem melhor estrutura"; "o nosso objetivo é o domínio do português e dos conteúdos das escolas dos brancos"; "a língua materna as crianças aprendem em casa e não precisam ir à escola para estudá-la"; "os professores não índios são mais preparados do que os professores indígenas"; "a cultura se aprende em casa".

Acrescentamos que algumas Escolas Indígenas se veem pressionadas pelo fechamento de sala de aula e agrupamento de várias classes numa só (multisseriação) e, consequentemente, dispensa dos professores contratados. As secretarias de educação, por sua vez, respondem ao Tribunal de Contas. No ano de 2018, o fenômeno de esvaziamento e de classes multisseriadas foi observado nas seguintes escolas: EM Indígena Velário Sucuriy (TI Sucuru'y), em Maracaju; EM Indígena Mbo-Ero Arandui (TI Jarara) e EM Indígena Mbo Eroga Taperandi Taquara (TI Taquara), em Juti. Nesses casos, todos os sujeitos envolvidos foram afetados diretamente.

Assim, entre obstáculos, desafios e ações vem ocorrendo o processo de 
implementação da EEI no TEE Cone Sul. Agora fica a pergunta: há interesse do atual governo federal em manter o Decreto n. 6861/2009 e o PNTEE/2013?

\section{Considerações finais}

Objetivamos traçar, aqui, um panorama macro no qual os entes federados são os principais responsáveis pela implementação das políticas educacionais, na medida em que compõem o poder executivo e seus órgãos gestores. Apresentamos, também, os movimentos das lideranças indígenas, que estão atentos, planejando, acompanhando e avaliando, por meio de suas organizações indígenas (Movimento de Professores Guarani/Kaiowá (MPGK), Aty Guasu - grande Assembleia do povo Guarani/Kaiowá -, e Fórum Estadual de Educação Escolar Indígena), e de seus lugares ocupados no Fórum Nacional de Educação Escolar Indígena e na Comissão Nacional de Políticas Indigenistas.

Percebemos que, apesar de as lideranças indígenas ocuparem espaços estratégicos, não conseguiram estruturar a Comissão Gestora do Território Etnoeducacional Cone Sul, nem a do Povos do Pantanal, para que, com autonomia administrativa e financeira, pudessem exercer a função de acompanhar e avaliar as ações do Plano de Ação dos TEE. Todavia, essas lideranças puderam intervir e demandar o Estado em suas instâncias local, estadual e nacional, por intermédio da organização dos movimentos indígenas. Desses movimentos saíram, de 2009 aos dias atuais, os documentos encaminhados aos diversos setores responsáveis pelo desenvolvimento do Plano de Ação, sempre com cópia para o Ministério Público Federal (MPF).

É fato que nenhum governo atendeu a contento às demandas da população Guarani/Kaiowá de Mato Grosso do Sul; contudo, é visível o protagonismo de suas lideranças no sentido de se organizarem para pautar seus interlocutores para acessar políticas públicas. Concomitante às ações educacionais estão as ações de retomada dos territórios de ocupação tradicional dos Guarani/Kaiowá. As organizações indígenas trazem consigo, em primeiro plano, a luta pela terra: "sem território indígena não tem educação escolar indígena". A luta pela terra é transversal às demais bandeiras.

Assim, se movimentam os indígenas e os demais órgãos e instituições, tais como as universidades, as secretarias de educação, as prefeituras e as entidades parceiras. A política do TEE Cone Sul vai se compondo, senão da forma desejável, mas da forma possível, conforme as interações vão se constituindo no campo da educação escolar indígena Guarani/Kaiowá. Desse modo vai se construindo a educação etnoterritorializada no Mato Grosso do Sul.

\section{Referências}

ANDRÉ, Marli Eliza Dalmazo Afonso. Etnografia da prática escolar. 16 ed. Campinas: Papirus, 2009. 
BOURDIEU, Pierre. O Poder Simbólico. Tradução de Fernando Tomaz. Rio de Janeiro: Bertrand Brasil, 2003.

BRASIL. MINISTÉRIO DA EDUCAÇÃO. Documento Final da I Conferência de Educação Escolar Indígena. Luziânia-GO, 16 a 20/11/2009. 2009a.

BRASIL. Decreto n. 6.861, de 27 de maio de 2009. Dispõe sobre a educação escolar indígena, define sua organização em territórios etnoeducacionais, e dá outras providências. Diário Oficial da União, Brasília, DF, n. 100, Seção 1, p. 23, 28 fev. 2009 b.

BRASIL. Lei n. 9.394, de 20 de dezembro de 1996. Estabelece as diretrizes e bases da educação. Diário Oficial da União, Brasília, DF, 23 dez. 1996.

BRASIL. Manifesto do XIX Encontro de Professores Guarani e Kaiowá de Mato Grosso do Sul, 2013. Documento não publicado - acervo particular do Movimento de Professores Guarani e Kaiowá (MPGK), 2013b.

BRASIL. MINISTÉRIO DA EDUCAÇÃO. Portaria n. 1.062, de 30 de outubro de 2013. Institui o Programa Nacional de Territórios Etnoeducacionais - PNTEE. Brasília, DF, 2013a.

BRASIL. MINISTÉRIO DA EDUCAÇÃO. Portaria n. 931, de 13 de julho de 2011. Diário Oficial da União, Brasília, n. 134, Seção 1, pág. 10, 14 jul. 2011.

CRESPE, Aline Castilho. Mobilidade e temporalidade Kaiowá: Do Tekoha à Reserva, do Tekoharã ao Tekoha. 2015. 428 p. Tese (Doutorado em História) - Programa de PósGraduação em História, Universidade Federal da Grande Dourados, Dourados, 2015.

LUCIANO, Gersem José dos Santos. Territórios etnoeducacionais: Comunicação apresentada na CONAE 2010. Brasília, CINEP, 2010.

LÜDKE, Menga; ANDRÉ, Marli Eliza Dalmazo Afonso. Pesquisa em educação: abordagens qualitativas. 2 ed. Rio de Janeiro: E.P.U., 2013.

NASCIMENTO, Adir Casaro; VIEIRA, Carlos Magno N. Escola Indígena Guarani/Kaiowá no Mato Grosso do Sul: experiência emancipatória de educação indígena. In: Anais do XXXVI Simpósio Nacional de História - ANPUH. São Paulo, 2011.

NASCIMENTO, Rita Gomes. Educação escolar indígena. Políticas e tendências atuais. Retratos da Escola, Brasília, v. 7, n. 13, p. 333-344, jul./dez. 2013.

NAZARENO, Elias. Revisitando o debate acerca da modernidade a partir da colonialidade do poder e da decolonialidade. Revista Nós: Cultura, Estética e Linguagens, Goiás, v. 2, n. 2, p. 32-49, set. 2017.

SAVIANI, Dermeval. O vigésimo ano da LDB: As 39 leis que a modificaram. Retratos da Escola, Brasília, v. 10, n. 19, p. 379-392, jul./dez. 2016.

SOUSA, Fernanda Brabo. territórios etnoeducacionais: contextualização de uma política de educação escolar indígena no Brasil. Políticas Educativas, Santa Maria, v.10, n. 1, p. 97$111,2016$. 
SOUSA, Fernanda Brabo. Sentindo ideias, germinando saberes: movimentos de apropriação (afetiva) da política de territórios etnoeducacionais por professores Kaingang e Guarani no RS. 2015. 428 p. Tese (Doutorado em Educação) - Programa de Pós-Graduação em Educação, Universidade Federal do Rio Grande do Sul, Porto Alegre, 2017.

VINHA, Marina. Educação escolar indígena: território etnoeducacional Cone Sul. Dourados: Editora da UFGD, 2016.

\section{Agradecimentos}

À CAPES pelo financiamento da bolsa de pós-doutorado (PNPD) e à UEMS/Programa de Pós-Graduação em Educação/Campus de Paranaíba-MS. 